\title{
Dementia Education in Higher Education Institutions
}

Dr Elizabeth Collier

Lecturer in Mental Health

University of Salford

Frederick Rd Campus

Salford

M6 6PU

e.collier@salford.ac.uk

$+0044(0) 1612952729$

Mr Chris Knifton

Senior Lecturer Dementia, Learning Disability and Mental Health

De Montfort University

Edith Murphy Building 7.08

The Gateway

Leicester

LE1 9BH

+0044 (0)1162013855

Chris Knifton cknifton@dmu.ac.uk

Dr Claire Surr

Reader in dementia Studies

Bradford Dementia Group

School of health Studies

University of Bradford

Bradford

UK

BD7 1DP

+44 (0) 1274236455

C.A.Surr1@bradford.ac.uk

\section{Key Words}

Dementia, education, skills, Teaching and learning

\section{Introduction}

Dementia is an umbrella term for a syndrome that can be caused by a range of disease processes, all of which are characterised by cognitive deficits including memory impairment, 
problems with language, motor functions, recognition of people or objects and disturbances to executive functioning (American Psychiatric Association 2000). It is estimated there are over 35.6 million people with dementia worldwide, with over 7.7 million estimated new cases each year and thus the total number of people with the condition set to almost double every 20 years (WHO 2012). Having a healthcare workforce skilled in providing high quality care to people with dementia is of international concern; and high quality dementia education must naturally underpin this ambition. Healthcare is a major employer internationally, for example in the UK the NHS employs more than 1.7 million people (NHS Choices 2013) and more than 11 million people work in healthcare in the US (Bureau of Labor Statistics 2011). Given people with dementia are a significant user of healthcare services, this means there are vast numbers of workers who need knowledge and skills in dementia care. This then raises a question of by whom and how this education is best provided.

\section{The role of Higher Education Institutions in dementia education}

As the major provider of education for health professionals internationally, and a key provider of continuing professional development opportunities, Higher Education Institutions (HEIs) clearly have a role to play in the provision of dementia education to the current and future healthcare workforce. Little is currently known about the quantity or content of dementia education provision within existing health programmes provided by HEIs. Pulsford et al. (2007) surveyed 22 universities in the UK and found in undergraduate courses leading to professional registration, there was limited input on dementia, ranging from 3 to 54 hours in mental health nursing programmes, 0 to 6 hours for adult nursing students, and 0 to 8 hours in both occupational therapy and social work courses. Similarly, Traynor et al. (2011) in mapping nursing curricula content in Australia and UK revealed an ad hoc and sparse inclusion of dementia education in undergraduate programmes. Where dementia was 
included in curricula, this was largely down to the presence of an individual staff member with knowledge, experience and above all a passionate interest, in dementia education.

To many of us working in the Higher Education sector this would be unsurprising; but how are HEIs and perhaps, more importantly, the individual staff members coping with what now may be seen as a growing demand? What impact is this having on the provision and quality of dementia education within HEI curricula? Certainly in the UK, HEIs are now required to provide evidence of meeting a variety of standards in dementia education in pre-qualifying curricula for health and social care professions. The question then has to be asked: where are the staff resources coming from for its delivery and how can we ensure those delivering the provision have adequate dementia specific expertise?

\section{Embedding dementia education in HEI curricula}

In the UK, interested individuals have been meeting together nationally since around 2000. The Higher Education for Dementia Network (HEDN) is supported by the charity Dementia UK and brings together academics involved in dementia education (Knifton et al., 2014) to discuss issues related to the delivery of dementia education within HEI settings. The network currently includes representatives from 53 Universities across the UK. A recent survey of HEDN members found that for almost every programme of study, there was a 'dementia lead' or its equivalent, undertaking the majority of dementia educational input. This creates a high demand on just a few individuals, which is an unsustainable model. There is a risk that dementia education will become a 'tick-box' exercise; an add-on or ad hoc approach; lectures not linked to other learning or assessment. This would have little meaning or value attached to it, nor any real impact on student's skills, attitudes and competency in caring effectively for people with dementia. 
For dementia education to be effective educators need to be able to help students understand its value to them in their current and future practice. Curricula content needs to address the full range of appropriate knowledge, skills and competencies that the future health, social care and medical workforce need to deliver high quality dementia care. To achieve this dementia education must embedded right across each programme curricula and interwoven into each appropriate module. For example modules on ethical issues, safeguarding, communication, and practical, profession specific skills all relate directly to the delivery of good dementia care.

We also need to recognise properly integrated dementia education is best taught by profession specific experts, who are best placed to weave the condition specific skills and knowledge into their academic modules and programmes. However, the people to whom this educational responsibility may fall may not themselves have had the opportunity to develop the required dementia expertise. This is creating a rapid gulf between the type of education many HEIs wish to deliver and what is feasible given current staff skills sets.

For many HEIs embedding dementia education meaningfully into their programmes is likely to be slow and painful. Individual academics tasked with this can feel overwhelmed by the enormity of the task and are not aware of what resources may be available to support them. Earlier this year, HEDN published a curriculum for dementia education (free to download http://www.dementiauk.org/what-we-do/networks/hedn/curriculum-for-dementia-education-

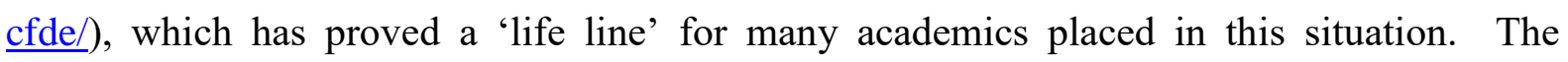
curriculum sets out academic outcomes from levels 4 to 7 in 12 domains. It is designed to be a guide, not a prescriptive document, offering a flexible and locally relevant approach. As 
the first ever HEI developed and agreed guide to a HEI focussed dementia curriculum, it is also being used to support the development of the curriculum for a European wide dementia programme (Posadem.eu). The HEDN CfDE was used as a core building block for recently launched principles and associated standards for dementia education within pre-registration programmes (Health Education South West 2014), which will be used to benchmark and commission education and training by Local education and Training Boards in England.

Whilst the HEDN curriculum provides a guideline for content, the All Parliamentary Group on Dementia (APPG, 2009) highlights the absence of a standardised curriculum in the UK. Standardised curricula may offer a pragmatic approach to ensuring national compliance, but it is not currently known what type of approach works best for dementia education (Traynor et al. 2011) and whether a single or multiple curricula will be required for a highly diverse health and social care workforce. Whatever the solutions, this is likely to be an area of significant development in the near future and may place additional demands on HEIs to respond rapidly to professional body or governmental requirements. Therefore, one of the greatest challenges to HEIs around dementia education will be the balance of 'doing it' versus 'doing it well'. Limited resources, a lack of dementia expertise across HEIs and within specific professions and rapidly changing demands from government and professional bodies will all influence the decisions made about how to approach this issue.

\section{Conclusions}

There are challenges to implementing dementia education across medical, health and social care education, which will continue to raise significant issues for how this is implemented in the near future. What is clear is that to deliver dementia education effectively will require the necessary commitment, time and resources from HEIs. There is currently a lack of dementia 
expertise across many HEIs to lead on this work, yet a high quality solution will require not just one, but a number of appropriately trained dementia lecturers need to be in place. Currently there are no ways of standardising the expertise, knowledge and skills of dementia lecturers at a national level in the UK (Traynor et al., 2011). Ultimately many HEIs may find the pressure to 'do it' will take precedence over 'doing it well'. Doing it well will need the health and social care workforce to have the necessary knowledge, skills and competence so that those who live with the condition can be confident in their future care.

\section{References}

All-Parliamentary Group on Dementia (2009) Prepared to Care-Challenging the dementia skills gap. London: Alzheimer's Society http://www.alzheimers.org.uk/site/scripts/download_info.php?fileID=735 [Accessed February 2014]

American Psychiatric Association. (2000). Diagnostic and statistical manual of mental disorders (4th ed., text rev.).doi:10.1176/appi.books.9780890423349.

Bureau of Labor Statistics, State Occupational Employment Statistics Survey, May 2011. Available at http://www.bls.gov/data/\#employment

Health Education South West (2014) Dementia education: Empirical development of curricula standards and criteria to support Dementia Education. Exeter: Health Education England. Available at: http://southwest.hee.nhs.uk/files/2014/12/dementia-educationcurricula-standards-and-criteria-2014.pdf

Knifton, C., Thompson, R., Tullo, E., Waugh, A., Surr, C., Read, K., Innes, A. (2014) Making a difference in dementia education. The Journal of Dementia Care 22(4): 18-21

NHS Choices (2013) About the National Health Service. Online: http://www.nhs.uk/NHSEngland/thenhs/about/Pages/overview.aspx accessed 14.8.14

Pulsford, D., Hope, K., Thompson, R. (2007) Higher education provision for professionals working with people with dementia: a scoping exercise. Nurse Education Today 27: 5-13 http://dx.doi.org/10.1016/j.nedt.2006.02.003

Traynor, V., Inoue, K., Crookes, P. (2011) Literature review: understanding nursing competence in dementia care. Journal of Clinical Nursing 20:1948-1960 doi: 10.1111/j.1365-2702.2010.03511.x

WHO (2012) Dementia: A public health priority. Geneva: WHO. Available at: http://www.who.int/mental_health/publications/dementia_report_2012/en/ 